\title{
Penerapan Gamifikasi Dalam Smart Tourism : Studi Literatur
}

\author{
Rifqi Asy'aria,1,*, Rusdin Tahir a,2, Cecep Ucu Rakhman b,3, Ayu Khrisna Yuliawati c,3
}

${ }^{a}$ Magister Pariwisata Berkelanjutan, Universitas Padjajaran Bandung - Indonesia

b Program Pascasarjana, Sekolah Tinggi Pariwisata Bandung - Indonesia

c Universitas Pendidikan Indonesia Bandung - Indonesia

${ }^{1}$ rifqi19015@mail.unpad.ac.id*; ${ }^{2}$ rusdin@unpad.ac.id; ${ }^{3}$ cecep.u.r@gmail.com; ${ }^{4}$ ayukrishna@upi.edu

\begin{abstract}
Tourism emphasizes the authenticity of an area with the principle of preservation and sustainable development, but technology is one factor that influences it enough to attract tourists or ease management in the tourism sector. The terminology of smart tourism appears as a direction in the support system for supporters in the tourism sector. One of the systems in implementing smart tourism is gamification, which is still a lot of ordinary people in the system. This article examines the extent of the application of gamification in the concept of smart tourism and what things are still obstacles in the application of gamification in the tourism industry so that it can be a recommendation for further research. So that both are expected to provide an understanding of the application of gamification and the extent of realization in the concept of smart tourism. The method used in this research is a literature study. The results obtained by the application of gamification in smart tourism are very helpful in the tourism industry. This system provides tourism development, namely providing education, utilizing the potential and use of technology. Gamification is a system where tourists are given more flexibility for activities and interacting with tourist areas, both visually and directly.
\end{abstract}

\begin{abstract}
ABSTRAK
Pada dasarnya pariwisata menekan keaslian dari sebuah kawasan dengan prinsip pelestarian dan pengembangan berkelanjutan, namun tenologi jadi satu faktor yang cukup mempengaruhinya untuk menarik wisatawan atau kemudahan pengelolaan dalam bidang pariwisata. Terminologi smart tourism muncul sebagai arahan dalam sistem pendukung bagi penujang bidang pariwisata. Salah satu sistem dalam penerapan smart tourism yaitu gamifikasi yang masih banyak kalangan awam dalam sistem tersebut. Artikel ini mengkaji terkait sejauh mana penerapan gamifikasi dalam konsep smart tourism dan hal apa saja yang masih menjadi hambatan dalam penerapan gamifikasi dalam industri pariwisata untuk kemudian dapat menjadi rekomendasi bagi penelitian selanjutnya. Sehingga keduanya diharapkan dapat memberikan pemahaman mengenai penerapan gamifikasi dan sejauh mana realisasi dalam konsep smart tourism. Metode yang dipergunakan dalam penelitian ini yaitu studi literatur. Hasil didapat penerapan gamifikasi dalam smart tourism sangat membantu dalam industri pariwisata. Sistem ini memberikan pengembangan pariwisata yaitu memberikan edukasi, memanfaatkan potensi dan penggunaan teknologi. Gamifikasi sebuah sistem dimana wisatawan diberikan keluasaan lebih buat beraktifitas dan berinteraksi dengan kawasan wisata baik itu visual maupun secara langsung.
\end{abstract}

\section{ARTICLE HISTORY}

Submitted: 11.06 .2021

Revised:08.07.2021

Accepted:09.07.2021

Online first:10.07.2021

\section{KEYWORDS}

Smart Tourism, Gamification, Tourism Development

\section{KATA KUNCI}

Smart Tourism, Gamifikasi, Pengembangan Pariwisata 


\section{Pendahuluan}

Peradaban terus berkembang dari masa ke masa, setiap bidang berlomba dalam perkembangan dari setiap peradabannya menuju kesempurnaan bidang diantaranya bidang pariwisata. Bidang pariwisata merupakan bidang yang multidisiplin ilmu yang membuat bidang ini dalam proses perkembangannya perlu didukung dari perkembangan bidang lainnya. Teknologi menjadi satu faktor yang, mempengaruhi perkembangan bidang pariwisata. Walaupun pada dasarnya pariwisata menekankan keaslian dari sebuah kawasan dengan prinsip pelestarian dan pengembangan berkelanjutan, namun teknologi jadi satu faktor yang cukup mempengaruhinya sebagai penarik atau kemudahan dalam perkembangan bidang pariwisata. Kemudahan dalam mengakses kawasan atau kebudayaan untuk memberikan pelayanan kepada wisatawan perlu didukung oleh teknologi sebagai supporting system ketika berada di kawasan pariwisata.

Supporting system dalam pariwisata membutuhkan ide kreatif dalam penciptaannya. Terminologi smart tourism muncul sebagai arahan dalam supporting system sebagai upaya menunjang bidang pariwisata. Smart tourism sendiri diartikan sebagai pemanfaatan segala potensi dan sumber daya yang ada untuk meningkatkan pengalaman di bidang Pariwisata. Konsep smart tourism terlahir dari pengembangan kajian mengenai hubungan teknologi dan bidang pariwisata (Gajdosik, 2018; Putra et al., 2020). Perkembangan smart tourism secara logis dari pariwisata tradisional yang berkembang menjadi e-tourism karena dasar inovasi dan orientasi teknologi industri dan konsumen diletakan diawal dengan adopsi ICT yang luas dalam kegiatan pariwisata (Pitanatri, 2020).

Konsep ini, menjadi konsep yang perkembangnnya cukup cepat di era modern ini namun pada dasarnya smart tourism tidak hanya perihal teknologi yang ada tehadap pengembangannya di bidang pariwisata tapi sebuah konsep untuk memberikan kemudahan dan kenyaman dalam bidang pawisata untuk menarik wisatawan atau pun mempermudah pengelola dalam melakukan pekerjaannya. Oleh daripada hal tersebut smart tourism menjadi gabungan konsep dari pengembangan inovasi teknologi dan informasi (Putra et al., 2020). Adapun, permodelan yang digunakan dalam menciptakan model pengalaman smart tourism melalui pemanfaatan diantaranya Big Data kepariwisataan, dikelola oleh DMO pariwisata dan perusahaan teknologi, ada permintaan dari wisatawan yang didukung dengan infrastruktur 
berbasis teknologi dan smart technologi, dan memperhatikan digital marketing yang efisien (Femenia-Serra et al., 2019). Dalam implementasi smart tourism terdapat satu konsep yang dinamakan kosep gamifikasi dimana konsep tersebut tubuh dalam menunjang pengembangan dalam bidang pariwisata.

Gamifikasi adalah desain game untuk masyarakat dengan tujuan non-game (Putra et al., 2020). Dalam industri pariwisata, gamifikasi telah diadopsi untuk meningkatkan identitas mereka (Foursquare, Brazil Quest Game), meningkatkan pengalaman wisatawan (REXplorer oleh Regensburg, Jerman), memanipulasi pergerakan turis (Geocoaching Tripadvisor), tingkatkan loyalitas pelanggan (Dapatkan sayap Anda melalui Udara Kanada), dan mengoptimalkan manajemen sumber daya manusia (Marriot My Hotel), dan tren ini berkembang terus menerus. Secara tradisional, industri pariwisata telah menggunakan program loyalitas berbasis frekuensi dan tur stempel, yang merupakan bentuk permainan paling sederhana yang digunakan pelanggan untuk mengumpulkan poin dan dapatkan insentif (Yoo et al., 2017). Namun, gamifikasi ini masih menjadi konsep baru dalam smart tourism sehingga penerapan dan proses dari gamifikasi ini masih sebagian orang yang paham dan mengerti.

Maka dari itu, artikel ini mengkaji terkait sejauh mana penerapan gamifikasi dalam konsep smart tourism dan hal apa saja yang masih menjadi hambatan dalam penerapan gamifikasi dalam industri pariwisata untuk kemudian dapat menjadi rekomendasi bagi penelitian selanjutnya. Sehingga keduanya diharapkan dapat memberikan pemahaman mengenai penerapan gamifikasi dan sejauh mana realisasi dalam konsep smart tourism.

\section{Review Tinjauan Pustaka}

Konsep smart tourism bertujuan untuk mengembangkan infrastruktur, kemampuan informasi dan komunikasi dalam upaya meningkatkan manajemen maupun tata kelola, inovasi produk, menciptakan ragam wisata, dan yang pada akhirnya menciptakan daya saing perusahaan yang dimana peran pariwisata adalah menjadi kebutuhan primer bagi pemerintah pusat/daerah untuk peningkatan sektor ekonomi nasional, dan smart tourism dapat memberikan arah yang menjanjikan untuk pengembangan pariwisata berkelanjutan dan memiliki potensi untuk mempengaruhi representasi mereka di pasar elektronik pada tingkat yang berbeda (Redjeki et al., 2018). Secara garis besar smart tourism memiliki tujuan untuk 
mengembangkan infrastruktur dan kemampuan informasi dan komunikasi untuk meningkatkan manajemen dari kawasan yang ada dengan memperhatikan peran pariwisata (Redjeki et al., 2019). Konsep smart tourism terdapat 13 elemen-elemen yang perlu diperhatikan dalam penerapannya diantaranya dijelaskan oleh Wang, Robert, Zhen, \& Zhang (2016) dalam Pinasthika \& Pradoto (2018) yaitu tourist attraction homepage, smart vehicle-scheduling, personalitinerary design, free wifi, smart cards, intelligent-guide system, crowd handling, mobile payment, tourist-flow monitoring, online information access, travel safety protection, e-tourism recommendation system, dan real time traffic broadcast. Selain itu, smart tourism memiliki tiga karakteristik yaitu (1) penggabungan industri pariwisata dengan teknologi informasi dan komunikasi,

(2) bersifat sosial dicirikan dengan interaksi sosial antara para wisatawan dan penduduk lokal,

(3) keterhubungan antara berbagai macam stakeholder terkait pengembangan industri pariwisata (Pinasthika \& Pradoto, 2018).

\section{Metodologi Penelitian}

Metode yang dilakukan dalam penelitian yaitu studi literatur. Peneliti melakukan review dari beberapa literatur mengenai penerapan gamifikasi dalam smart tourism. Penelitian kepustakaan atau studi literatur sendiri diartikan sebagai penelitian yang dilakukan hanya berdasarkan atas karya tertulis, termasuk hasil penelitian baik yang telah maupun yang belum dipublikasikan (Embun, 2012; Melfianora, 2017). Data-data yang dibutuhkan dalam penelitian dapat diperoleh dari sumber pustaka atau dokumen dan variabel pada penelitian studi literatur bersifat tidak baku (Melfianora, 2017). Penelitan ini mengacu kepada metode konseptual yang digunakan seperti dikatakan Pitanatri (2020) dalam penelitiannya terkait konseptualisasi terminologi flashpacker dalam berbagai kajian literatur dan model pengembangan riset. Maka metode dalam penelitian ini menekankan pada metode kualitatif berupa studi literatur. teknik pengumpulan data yang dilakukan secara kualitatif melalui penelusuran dari berbagai literatur (riset kepustakaan), seperti buku dan jurnal (Pitanatri, 2020). Data yang dianalisis merupakan data sekunder yang didapatkan dari beberapa literatur berkaitan gamifikasi dalam implementasi smart tourism. Adapun, alat bantu pencarian yang digunakan adalah harzing's publish or perish. Selanjutnya data dianalisis dengan metode tinjauan pustaka dengan teknik traditional review. 
Table 1. Literatur Terkait Gamifikasi dan Smart Tourism

\begin{tabular}{llll}
\hline Kode & \multicolumn{1}{c}{ Judul/Tahun Terbit } & Peneliti & Penerbit \\
\hline 1 & $\begin{array}{l}\text { Design of Smart Gamification In Village Tourism: } \\
\text { An Indonesian Case Study (2020) }\end{array}$ & Bahtiar et al. & $\begin{array}{l}\text { International Journal of Engineering } \\
\text { Pedagogy }\end{array}$ \\
\hline 2 & $\begin{array}{l}\text { Serious games and the gamification of tourism } \\
\text { (2017) }\end{array}$ & Shui \& Xu & Tourism Management \\
\hline 3 & $\begin{array}{l}\text { Factors Affecting the Adoption of Gamified Smart } \\
\text { Tourism Applications: An Integrative Approach } \\
\text { (2017) }\end{array}$ & Yoo et al. & Sustainability (Switzerland) \\
\hline 4 & $\begin{array}{l}\text { Gamification techniques in tourism, application } \\
\text { test, Casa Mosquera Museum (2015) }\end{array}$ & Borrero et al., & Sistemas y Telemática \\
\hline
\end{tabular}

Studi literatur ini dilakukan dengan kriteria artikel ilmiah yang memiliki dua kata kunci yaitu gamification dan smart tourism. Didapat sepuluh (10) artikel yang dapat, namun pada proses pengambilan artikel peneliti terkendala dari banyaknya artikel yang ada dalam proses mengunggah memerlukan biaya sehingga penelitian mengerucutkan artikel yang sudah didapat dengan memberikan syarat dapat di unggah secara gratis. Didapat 4 artikel yang sesuai kriteria dan syarat yang telah ditetapkan dan menjadi artikel yang dianalisis oleh peneliti (tabel 1).

\section{Hasil dan Diskusi}

Perwujudaan smart tourism yang di artikan dari artikel yang ada bahwa konsep ini dibuat agar masyarakat dapat terdidik dengan kehidupan berwisata, maka diperlukan teknologi yang tepat guna dalam pengembangan pariwisata. Salah satunya adalah gamifikasi yang merupakan teknologi atau inovasi dapat implementasikan dalam dunia pariwisata yaitu pada pariwisata pendidikan. Tujuannya gamifiaksi untuk memotivasi dan mengatasi kurangnya partisipasi wisatawan yang berkunjung untuk mendapatkan pengalaman yang berupa pendidikan dari kawasan yang dikunjungi. Gamifikasi juga diterapkan untuk membangkitkan rasa empati terhadap lingkungan.

Dilihat dari hasil analisis tujuan yang dipapat untuk mengubah pola aktivitas pengunjung yang sebelumnya hanya berfoto saja, tetapi juga diajak untuk mengeksplorasi potensi kawasa melalui aplikasi mobile. Selain itu, dengan penerapan gamifikasi mendorong sekaligus membantu melestarikan kawasan pariwisata, untuk mengenalkan secara mendetail untuk wisatawan, dan mengubah perilaku masyarakat demi kesehatan dan kesejahteraan dalam bentuke-health. Efektivitas jangka panjang diperlukan untuk bangun dengan mengeksploitasi 
pengalaman inti dan efek psikologis mekanisme permainan. Juga, gamifikasi desain harus secara tegas menempatkan penelitian dan diskusi desain dalam teori manajemen dan studi kritis. Sehingga diharapkan gamifikasi dapat membantu proses transformasi dari berbagai kendala yang menghalangi berdasarkan mekanisme gamifikasi emosional.

Implementasi yang dipaparkan dalam artikel 1 dimana gamifikasi ini dibuat untuk mengeksplor desa wisata melalui mobile dan dimana wisatawan akan mendapatkan penghargaan (reward) dari game yang berupa misi yang harus di selesaikan oleh wisatawan. Gamifikasi akan meningkatkan motivasi belajar tentang desa wisata dengan cara yang menyenangkan. Penentuan tim kemudian sistem kompetisi dan kolaborasi akan memainkan peran penting dalam proses transformasi. Sehingga pengguna akan menjadi salah satu promosi dan daya tarik unggulan dalam mengembangkan potensi wisata desa yang lebih modern dan menyenangkan. Penggunaan gamifikasi berbasis aplikasi mobile dinilai sangat tepat untuk menanamkan pengetahuan tentang wisata desa pada siswa sekolah dasar. Gamifikasi ini mengharuskan siswa menyelesaikan misi bertani secara berkelompok dengan smartphone mereka untuk mendapatkan pendidikan pertanian. Imbalan diberikan secara intensif agar siswa lebih semangat dalam mencapai misi ini. Temuan penelitian ini adalah penghargaan yang disukai oleh siswa sekolah dasar berupa point yang didapat di akhir yang dapat di tukarkan dengan hadiah.

Adapun, penerepan gamifikasi dilakukan dalam artikel 4 yang penerapan yang dilakukan menggunakan mobile yang terhubung dengan map dari museum wisatawan diajak menelusuri bagian-bagian dari museum tersebut untuk membereskan sebuah misi. Wisatawan di ajak untuk memfoto, membaca, dan berdiskusi. Aktifitas ini memberikan ruang edukasi yang tinggi dalam memberikan pengalaman bagi wisatawan yang ada. Pada akhirnya wisatawan tersebut yang telah membereskan semua game yang dilakukan akan di beri penghargaan (reward) oleh pengelola dan menjadi daya tarik sendiri bagi wisatawan yang ingin berkunjung ke tempat tersebut.

Pada dasarnya smart tourism merupakan konsep pariwisata yang menekankan pada pengalaman yang mendidik untuk wisatawan yang digabungkan melalui pontesi wisata dan teknologi yang ada. Gamifikasi berupa game yang mengharuskan wisatawan membereskan 
satu misi ketika berada di kawsan wisata mengunakan perantara teknologi yang disini alat tersebut merupakan smartphone sudah mencirikan karakteristik dari smart tourism sebagai penggabungan industri pariwisata dengan teknologi informasi dan komunikasi.

Gamifikasi bersifat sosial dalam produk yang diberikan karena bentuk dari sarananya dalah permainan yang dimana smart tourism perlu menciptakan interaksi sosial antara para wisatawan dan penduduk lokal. Dalam proses penciptaan gamifikasi yang dibahas dalam artikel yang dianalisis memerlukan keterhubungan antara berbagai macam stakeholder terkait pengembangan nya dalam bidang pariwisata. Permasalahan dari penerapan gamifikasi ini dari hasil analisis yang ada yaitu penerapan ini membutuhkan insfrastruktur yang cukup memadai yaitu jaringan telekomunikasi dan kemampuan pengelola dalam penerapan gamifikasi ini. dari hasil analisis sistem ini masih perlu dilakuan penelitian lebih lanjut perihal implementasinya sehingga dapat diterapkan untuk membantu kemajuan gagasan pariwisata khususnya pariwisata pedesaan atau dalam bentuk ruang (kawasan) dan dapat membantu konsep smart tourism dalam memperkokoh konsepnya.

\section{Kesimpulan}

Penerapan gamifikasi dalam smart tourism sangat membantu. Sistem tersebut memberikan pengembangan yang sama yaitu memberikan edukasi, memanfaatkan potensi dan penggunaan teknologi. Gamifikasi sebuah sistem dimana wisatawan diberikan keluasaan lebih buat beraktifitas dan berinteraksi dengan kawasan wisata baik itu visual maupun secara langusung. Gamifikasi sendiri membutuhkan integrasi antar stakeholder dalam proses pengembangnnya dalam kawasan wisata yang sangat memberikan implementasi keterhubungan terhadap konsep dari smart tourism.

Kendala yang perlu diantisipasi dari penerapan sistem ini dalam smart tourism yaitu ketersediannya jaringan telekomunikasi. Penelitian yang dapat dilakukan selanjutnya yaitu menelah efektifitas gamifikasi ini dari sudut kawasan. Penelitian ini masih minim dilakukan yang menjadi peluang yang dapat dilakukan oleh peneliti selanjutnya. Penggunaan metode kualitatif sangat menjadi rekomendasi karena masih minimnya penerapan metode ini dalam penelitian yang dilakukan. 


\section{Author's declaration}

\section{Authors' contributions and responsibilities}

$\sqrt{ }$ The authors made substantial contributions to the conception and design of the study.

$\sqrt{ }$ The authors took responsibility for data analysis, interpretation and discussion of results.

$\sqrt{ }$ The authors read and approved the final manuscript.

\section{Availability of data and materials}

$\sqrt{ }$ All data are available from the authors.

\section{Competing interests}

$\sqrt{ }$ The authors declare no competing interest. 


\section{References}

[1] Bahtiar, A. R., Segara, A. J. T., \& Suyoto. (2020). Design of smart gamification in village tourism: An Indonesian case study. International Journal of Engineering Pedagogy, 10(1), 82-93. https://doi.org/10.3991/ijep.v10i1.11522

[2] Borrero, F., Sanjuán Muñoz, P. C., \& Ramírez González, G. (2015). Técnicas de gamificación en el turismo, prueba de aplicación, Casa Museo Mosquera. Sistemas y Telemática, 13(33), 63-76. https://doi.org/10.18046/syt.v13i33.2081

[3] Femenia-Serra, F., Neuhofer, B., \& Ivars-Baidal, J. A. (2019). Towards a conceptualisation of smart tourists and their role within the smart destination scenario. Service Industries Journal, 39(2), 109-133. https://doi.org/10.1080/02642069.2018.1508458

[4] Melfianora. (2017). Penulisan Karya Tulis Ilmiah Dengan Studi Literatur. Studi Litelatur, 1-3.

[5] Pinasthika, N., \& Pradoto, W. (2018). Potensi dan Tantangan Pengembangan Kawasan Kota Lama Semarang sebagai Destinasi Wisata dengan Pendekatan Smart Tourism. Teknik PWK (Perencanaan Wilayah Dan Kota), 7(3), 153-164. http://ejournal3.undip.ac.id/index.php/pwk

[6] Pitanatri, P. D. S. (2020). Wisatawan Flashpacker: Sebuah Pendekatan Epistemologis. Jurnal Master Pariwisata (JUMPA). https://doi.org/10.24843/jumpa.2020.v07.i01.p04

[7] Putra, R. R., Siti Khadijah, U. L., \& Rakhman, C. U. (2020). Pemanfaatan Teknologi Informasi dan Komunikasi dalam Penerapan Konsep Smart Tourism di Kabupaten Pangandaran. Jurnal Master Pariwisata (JUMPA), 7, 257. https://doi.org/10.24843/jumpa.2020.v07.i01.p12

[8] Redjeki, S., Faizal, E., Iskandar, E., Rosadi, D., \& Mustofa, K. (2018). Model Sistem Wisata Integratif : Sebuah Pendekatan Smart Tourism di Kabupaten Bantul. Seminar Nasional Teknologi Informasi Dan Komunikasi (Semnastik 2018), 16-25. https://drive.google.com/file/d/1jAGzaLOEFMVl9yXdTFrTBAjspk9xcWQ/view?usp=sharing

[9] Redjeki, S., Faizal, E., Iskandar, E., Rosadi, D., \& Mustofa, K. (2019). Framework Pengembangan City Branding Kabupaten Bantul Menggunakan Pendekatan Smart Tourism. Jurnal TAM (Technology Acceptance Model), 9. http://www.ojs.stmikpringsewu.ac.id/index.php/JurnalTam/article/view/656

[10] Shui, W., \& Xu, G. (2016). Analysis of the influential factors for changes to land use in China's Xingwen Global Geopark against a tourism development background. In Geocarto International (Vol. 31, Issue 1). https://doi.org/10.1080/10106049.2015.1041558

[11] Yoo, C., Kwon, S., Na, H., \& Chang, B. (2017). Factors affecting the adoption of gamified smart tourism applications: An integrative approach. Sustainability (Switzerland), 9(12), 1-21. https://doi.org/10.3390/su9122162 